Volume 1

Number 2 Secrecy and Authoritarianism

February 2018

\title{
\#whitegenocide, the Alt-right and Conspiracy Theory: How Secrecy and Suspicion Contributed to the Mainstreaming of Hate
}

Andrew F. Wilson

University of Derby, UK, a.f.wilson@derby.ac.uk

Follow this and additional works at: https://scholarworks.sjsu.edu/secrecyandsociety

Part of the Communication Technology and New Media Commons, Social Influence and Political Communication Commons, Social Media Commons, and the Sociology Commons

\section{Recommended Citation}

Wilson, Andrew F.. 2018. "\#whitegenocide, the Alt-right and Conspiracy Theory: How Secrecy and Suspicion Contributed to the Mainstreaming of Hate." Secrecy and Society 1(2). https://doi.org/10.31979/2377-6188.2018.010201 https://scholarworks.sjsu.edu/ secrecyandsociety/vol1/iss2/1

This Article is brought to you for free and open access by the School of Information at SJSU ScholarWorks. It has been accepted for inclusion in Secrecy and Society by an authorized administrator of SJSU ScholarWorks. For more information, please contact scholarworks@sjsu.edu.

\section{(c) (1) @}

This work is licensed under a Creative Commons Attribution-Noncommercial-No Derivative Works 4.0 License. 


\title{
\#whitegenocide, the Alt-right and Conspiracy Theory: How Secrecy and Suspicion Contributed to the Mainstreaming of Hate
}

\author{
Abstract \\ This article considers the relationship between "hashtag activism" as it is currently being \\ used by the alt-right and the tendency to draw on conspiracy theory that Richard \\ Hofstadter identified as being prevalent among what he termed "pseudo-conservatives" \\ half a century earlier. Both the alt-right and Hofstadter's "pseudo-conservatives" can be \\ characterised by a pronounced populist nationalism that understands its aims as protecting \\ a particular way of life whilst drawing on an aggrieved sense of injustice at being conspired \\ against by an unseen enemy. That this "enemy" is typically foreign in actuality or in spirit \\ confirms the cultural dimension on which their politics is played out. It is argued here that \\ this paranoid populist nationalism has been figuratively drawn upon in the rhetoric of \\ Donald Trump and that this apparent openness to the "pseudo-conservative" discourse on \\ nationalism has provided a bridging effect via which far right elements are seeking to \\ normalize extremist viewpoints.
}

\section{Keywords}

alt-right, conspiracy theories, hashtag activism, pseudo-conservatives, Richard Hofstadter, secrecy, Donald J. Trump, Twitter, white nationalism 


\title{
\#whitegenocide, the Alt-right and Conspiracy Theory: How Secrecy and Suspicion Contributed to the Mainstreaming of Hate
}

Andrew Fergus Wilson

\begin{abstract}
This article considers the relationship between "hashtag activism" as it is currently being used by the alt-right and the tendency to draw on conspiracy theory that Richard Hofstadter identified as being prevalent among what he termed "pseudo-conservatives" half a century earlier. Both the alt-right and Hofstadter's "pseudo-conservatives" can be characterized by a pronounced populist nationalism that understands its aims as protecting a particular way of life whilst drawing on an aggrieved sense of injustice at being conspired against by an unseen enemy. That this "enemy" is typically foreign in actuality or in spirit confirms the cultural dimension on which their politics is played out. It is argued here that this paranoid populist nationalism has been figuratively drawn upon in the rhetoric of Donald Trump and that this apparent openness to the "pseudo-conservative" discourse on nationalism has provided a bridging effect via which far right elements are seeking to normalize extremist viewpoints.
\end{abstract}

Keywords: alt-right, conspiracy theories, hashtag activism, pseudoconservatives, Richard Hofstadter, Donald J. Trump, Twitter, white nationalism

Kellyanne Conway's phrase "alternative facts" has already passed into notoriety; the Counselor to the U.S. president used the phrase when defending statements relating to the size of Donald Trump's inauguration crowd made by former Press Secretary Sean Spicer (Blake 2017). Whilst the 
Secrecy and Society, Vol. 1, No. 2 [2018], Art. 1

phrase was largely ridiculed by the "mainstream media" (MSM), their scorn is unlikely to have had much impact on significant sections of Trump's support. Not only is the MSM trusted by less than a third of U.S. citizens (Swift 2016), but there has been a resurgence of the acceptability of conspiracy theory, or "the paranoid style" as it was described by Richard Hofstadter during the 1960s. In his essay published in Harpers, Hofstadter described the "dispossessed" feeling that characterized the right wing of American politics in 1964 . Indicative of the current state of political discourse, half a century later Alex Jones, founder and frontman of the conspiracy clearing house Infowars.com, claimed that he was one of the first people that Donald Trump spoke to in his capacity as president (Haberman 2016). Trump has ridden a wave of populist dissent into the White House and has done so using rhetoric drawn from recent conspiracy theory. The conspiracy theories publicly embraced by Trump include the idea that climate change is "a Chinese hoax" (Trump 2012), that Barack Obama is not a U.S. citizen (Krieg 2016), Barack Obama as the founder of ISIS (Siddiqui 2016), vaccines cause autism (Trump 2014), and Muslims celebrated the 9/11 attacks en masse in New Jersey (Kessler 2016). ${ }^{1}$ This latter convergence of conspiracy, ethnicity, and populist politics encapsulates the scope of this article. This article will also examine the shared conceptual spaces of populist politics, conspiracy theory and the role of the Internet in

1 It is worth noting Pasek et al's (2016) study that connected belief in the "birther" conspiracy with anti-Black sentiment. 
facilitating the mainstreaming of the paranoid style. By looking at far right communications strategies within the conspiracy milieu, it will be shown that the presence of conspiracy theories in the public sphere has allowed white nationalist discourse to gain increased exposure. It should be noted that the primary concern here is to concentrate on the effect on public discourse of demonstrably untrue conspiracy theories. That these types of conspiracy theories currently proliferate and determine much of the discussion should not deflect from efforts to uncover the very real conspiracies that often accompany statecraft and political maneuvering; Russian interference in the 2016 U.S. presidential election is testament to that. Rather, the focus here is on those conspiracy theories that were formerly marginal and stigmatized due to their lack of verifiability.

\section{Theories of Conspiracy Theories}

Conspiracy theory thrives in an environment of secrecy and necessarily so. Without the possibility of there being a mechanism by which any plot might be hidden there would be no opportunity to postulate the kind of hidden malevolent plots that fuel conspiracy theories. So, secrecy and conspiracy theories are not unrelated phenomena. Certainly, this is not the only causal factor in the production of conspiracy theory but, in general terms, a poverty of information can be understood to be productive of a tendency to "fill in the gaps" in a simplistic and reductive manner. This is, in 
Secrecy and Society, Vol. 1, No. 2 [2018], Art. 1

essence, the motive behind Fredric Jameson's $(1988,356)$ well-known description of conspiracy theory as "the poor person's cognitive mapping in the postmodern age; it is a degraded figure of the total logic of late capital." In Jameson's reading, class-based barriers to opportunity for knowledge acquisition and the development of critical reason are the limiting factors that reproduce information poverty. More typically, the extension of state mechanisms for the production, classification, and suppression of information are understood to be the primary factors in the development of the current conspiracy milieu. Whilst this atmosphere of secrecy contributes to a conspiracist tendency, as will be seen, status insecurity, fragile economic wellbeing, and global economic developments also contribute.

Secrecy does not automatically produce conspiracy theories, or, indeed, entail actual conspiracies. Daniel Hellinger (2003) quite rightly describes a number of scenarios in which the use of secrecy by the state or special interest groups may be required operationally, to facilitate frank discussion, or to protect national interests. All of these may be pursued legitimately in secret. However, they become conspiratorial when they operate outside of agreed frameworks or subvert the democratic process (Hellinger 2003). It should be noted here that conspiracy theorists can perform a valuable role; their investigative skepticism offers a vital challenge to the concealment or reduced circulation of information whilst also challenging the assumptions that contribute to the definition of "the national 
interest." As such, they can provide a means for redressing the asymmetrical balance of power that state secrecy contributes to (Maret 2016). Conspiracies do happen and are facilitated by an opaqueness in corporate and state business. It is easy enough to identify any number and discussion of conspiracies in the field of U.S. politics would only be controversial in selecting a single example over other possibilities: the Tuskegee syphilis experiment, Project MKULTRA, the assassination of JFK, Watergate, or the Iran-Contra affair might all merit consideration and bring to light distinct forms of information control. In an environment in which secrecy abounds, and in which conspiracies are shown to occur after the fact, it should be unsurprising that the public is ready to speculate about current conspiracies. However as Fenster (2008) points out, the proliferation of conspiracy theories and the staggering diversity and likelihood of their claims makes it difficult to assess the veracity of conspiracy claims. This, in turn, allows conspiracy theory to serve multiple political ends as a result of this indeterminacy: the hidden enemy is always secretly at work to undermine and destroy "our" way of life and that "we" must stand together to oppose "them." Oliver and Wood's $(2014,964)$ study of conspiracy theory belief found that within the U.S. adult population:

Not only does half of the American population agree with at least one conspiracy from a short list of conspiracy theories offered, but also large portions of the population exhibit a strong dispositional inclination toward believing that unseen, intentional forces exist and that history is driven by a Manichean struggle between good and evil. 
The readiness to believe in a hidden, Manichean battle as a hidden hand in the passage of history indicates a susceptibility to the kind of manipulation via conspiracy narratives outlined by Fenster. Nonetheless, Fenster (2008) situates conspiracy theory as a response to the development of a monopoly on information and the production of "truth"; he is, ultimately, a celebrant of the kind of agency that the production of conspiracy theory offers. In this analysis, it is a way out of Jameson's information poverty motivated by a suspicion of the secret state. Fenster (2008, 278 ) concludes his book with a narrative voice that is an unclear convergence of his own and the narrator of the 9/11 "truther" documentary Loose Change, a move he suggests is empowering to viewers bereft of their own, clear voices, which

gives the viewer meaning and agency, and offers a sense of adventure and fun as she attacks the stodgy, conspiratorial state with the latest information technology and Web portals. And the conspiracy community is the collective response that can rally the people and restore the nation. The truth movement, composed of great scholars and regular kids with laptops, can overcome.

Fenster captures the seductive power of contemporary conspiracy theory, leaving open the possibility of a politically mobilized community of "web researchers" enriching their cognitive maps and breaking down barriers to "true" knowledge. As if in recognition of the lack of criticality, this ending suggests an afterword that recognizes the limited opportunity for conspiracy 
theory to grow into a structured and productive politics that can, "organize and respect people in the complex, diverse world that it simplifies" (Fenster 2008, 289).

Fenster makes an attempt to understand conspiracy theory as a search for agency in an information economy in which access to knowledge production is ostensibly limited, but can be extended and challenged by the communicative strategies of the Internet. Fenster's work, in its first edition (1999), was an important intervention that captured a moment characterized by an organic upswell of political awareness. Here Barkun (2003) offers a useful summary of the value of the Internet to the conspiracy theorist. Barkun highlights the value of an open medium of communication that is free from gatekeepers to conspiracy theorists. Unlike the MSM's capacity to regulate and assess the quality of knowledge production, the Internet offers conspiracy theorists the opportunity to circulate their ideas freely without fear of their theories being dismissed as spurious, "stigmatized knowledge subcultures are at a distinct disadvantage as far as mass media are concerned [...] Consequently, those whose worldview is built around conspiracy ideas find in the Internet virtual communities of the like-minded" (Barkun 2003, 13). Nonetheless, that does not diminish widespread tastes for MSM treatments of conspiracy theory and within the cultural sphere the entertainment industry has exploited a generalized atmosphere of suspicion and mistrust. The most significant 
recent works on conspiracy theory bear witness to this and Knight (2000), Goldberg (2001), Barkun (2003), and Fenster (2008) all point to the influence of the television series The X-Files (1993-) in expanding public knowledge of conspiracy theory whilst drawing its popularity from an environment of distrust. The stuff of The $X$-Files is standard conspiracy fare. It depicts a complex and hidden world in which a shadow government operated behind the scenes and conspired against its citizens and, in its most dramatic sweep, humanity as a whole. The program's slogan "The Truth is Out There" featured in the title sequence, epitomizes the troubled relationship with "the truth" that is currently experienced by the subject in late modernity. The truth is "out there" in the sense that it is always somewhere else, hidden in the general welter of the information, concealed behind disinformation or hidden, restricted from the public. ${ }^{2}$ For Goldberg (2001, 256), this outlook typifies a historical moment in which an actively maintained veil of secrecy separates state and citizenry. He describes "a cult of secrecy [that] has dominated the bureaucracy in Washington and distanced federal authorities from those beyond the beltway," and that this commitment to secrecy-in-the-name-of-security has proliferated and accelerated in the post-WWII period so that its maintenance has now become more "reflex" than "necessity" (Goldberg 2001, 256). Moreover, this culture of secrecy has proven fertile ground for the genesis and growth of conspiracy theory. In Goldberg's (2001, 257) words,

2 One $X$-Files episode was tellingly titled "All Lies Lead to the Truth." 
Concealed information denied accountability and enabled the arrogant both to ignore public opinion and to manipulate it. Behind this veil, laws were broken and democratic values subverted [...] Even without the taint of malevolence, suppression of information aroused concern [...] Drawing sustenance from America's resilient fear of centralized authority, perceptions of sinister design became truth.

This phenomenological correspondence between conspiracy and innuendo is key here, especially where it is coupled with a population increasingly disconnected from a central authority and experiencing perceptions of social and economic disempowerment. Knight (2000) also depicts a labyrinthine architecture of secrecy characterizing the American state as it developed during the Cold War. He describes a "sprawling intelligence community" comprised of "the CIA, the National Security Council, the Defence Intelligence Agency, the National Security Agency, Army Intelligence, Navy Intelligence, Air Force Intelligence, the State Department's Bureau of Intelligence and Research, the Atomic Energy Commission and the FBI" (Knight 2000, 28). Knight's (2000, 29) reading of this proliferation of the secrecy-oriented state is similar to Goldberg's and he finds that this "official obsession with secrecy, in effect, helped fuel the popular fixation on conspiratorial secrets at the heart of government." Knight's analysis suggests that contemporary America is experiencing a "culture of conspiracy" in which the widespread intelligence community is generative of a dispersed and generalized fascination with secrecy and occulted machinations. As will be noted below, it is from this position that he 
Secrecy and Society, Vol. 1, No. 2 [2018], Art. 1

dismisses Hofstadter's narrow focus on conspiracy as being the purview of extremists. Knight is right to draw attention to the extent that this culture of conspiracy can be the groundswell from which a healthy critical mindedness emerges. However, it should also be acknowledged that there is an increased acceptance of a politics that was once considered to be extreme but which, concurrently with conspiracy theory, is becoming increasingly mainstream. As this article suggests, this concurrence is beyond coincidence; it is a consequence of the extent to which far right usage of conspiracy theory has become so thoroughly interwoven in the conspiracy milieu as to ensure that an articulation of current conspiracy theories is to evoke political positions on the extreme right, wittingly or not.

\section{Conspiracy Theories and the Radical Right}

The coincidence of belief in conspiracy theory and extremist politics is widely noted in the literature (e.g., Dobratz \& Shanks-Meile 2000, Gardell 2002, Goodrick-Clarke 2003, Durham 2007). Both tend to share an apocalyptic structure in which communal ontologies are threatened by external forces; typically, in both instances, these forces are hidden and their threat to the extremist/conspiracy theorist's community is realized through secondary agents and secret plots. Richard Hofstadter's scenesetting and frequently maligned essay "The Paranoid Style in American Politics" paints a picture of the conspiracy theorist's self-appointed role as a protector of a world threatened by the machinations of hidden conspirators. 
Whilst there are conspiracy theories that can be seen to be written from a left-wing perspective, it is the political right wing that has come to be more readily associated with the production and belief in conspiracy theories. This is not surprising. The political right are, generally speaking, socially and culturally conservative with an ongoing association with "traditional values" so the belief of a secret adversary - be it Satan, communism, the Illuminati, the New World Order or whomever - that is plotting to radically transform society's values is a clear threat to a conservative mindset. Here, then, conspiracy is understood as Barkun's recursive "super conspiracy" implemented to bring about an apocalyptic endtime. This paper contends that the political extremity of white nationalism seeks to play on the fear of an adversarial "hidden hand" in order to provide a platform from which to normalize their politics of hate. In this, Richard Hofstadter's work is of continuing value in the analysis of far right discourse and provides an explanatory model for understanding the political right in the U.S. This will be done in the context of the use of the Twitter hashtag "\#whitegenocide."

In 2011, Gary Kamiya wrote a piece titled, "The Infantile Style in American Politics" for Salon. In it, Kamiya argued that Hofstadter's essays "The Pseudo-Conservative Revolt - 1955" and "Pseudo-Conservatism Revisited - 1965" provided a way of understanding the Tea Party movement within the Republican party. A year earlier the left-leaning conservative 
blogger Andrew Sullivan (2010) wrote a similar but shorter piece titled "Trying To Understand The Tea Party II" for his blog. Both writers drew on Hofstadter's distinction between "pseudo-conservatives" and "genuine conservatives" and this distinction will be useful to the current examination of the right-wing populism evident in Donald Trump's recent election and the emergence of the so-called alt-right.

Not without controversy, Hofstadter's two essays concerning the "pseudo-conservative" political tendency in the U.S. give an account of the nationalism and prejudice present within U.S. populism from the late Nineteenth Century onwards. Foreshadowing current populist formations, he identified a conspiratorial outlook within these populist movements. The origin of the conspiracy was, typically, European bankers and, on occasion, Jewish bankers working with foreign powers or for themselves. Hofstadter identified jingoistic and anti-Semitic tendencies in the populist US People's Party of the 1890s. His portrayal of them is complex but he was generally well-disposed toward them, seeing them as "mild radicals" who targeted the monied elites of their day. Although there was contestation over the extent to which status anxiety was a motivating factor for the Populists (Collins 1989), in Hofstadter's analysis the primary motivation was economic anxiety with status anxiety a secondary factor as is made clear in the correspondence cited by Collins. Nonetheless, status anxiety is acknowledged as being a contributory factor and Hofstadter expands upon 
the contribution of status anxiety to populist anti-intellectualism in the $1950 \mathrm{~s}$ in the essay "The Pseudo-Conservative Revolt" (1955, in Bell 1963). The prejudice described by Hofstadter in this essay has value to the current discussion in its depiction of the American political situation of the 1950s. The essay starts with Hofstadter reflecting upon the situation of a generation that had been forged in the "liberal dissent" of the 1930s that had led to the New Deal. Hofstadter suggests that by the time of writing this generation had retained their liberal inclinations but had become politically conservative; in a condition of relative affluence, they had a desire to retain the advantages that the prevailing order provided them. He contrasts them to the group he identified as the dominant radical force of the time, the pseudo-conservatives. He draws on Adorno et al's (1950) study of the authoritarian personality.

Adorno and his co-researchers initially sought to determine causal factors in an individual's development of anti-Semitic beliefs but broadened their concerns to try and understand the formative influences contributing to a generalized susceptibility to an ethnocentric, authoritarian outlook. The study is methodologically flawed (something Hofstadter acknowledges in the later essay, "Pseudo-Conservatism Revisited - 1965"), but it formulates an emerging tendency in post-War US politics that, it is argued here, characterizes the "right wing identity politics" of the alt-right and recent formations within white nationalism. Adorno distinguishes between "genuine 
Secrecy and Society, Vol. 1, No. 2 [2018], Art. 1

conservatism" and "pseudo conservatism" by characterizing the former as a perceived protection of "positive" conservative values and a vision of America as a land of opportunity for all within the terms of democratic capitalism. The latter contains elements of that aspirational narrative but they are overshadowed by a rigidly hierarchical ethnocentric framing of it. In effect, opportunity is only available to certain in-groups. From Adorno (1950, 182)，

The ethnocentric conservative is the pseudo conservative, for he betrays in his ethnocentrism a tendency antithetical to democratic values and tradition [...] his politico-economic views are based on the same underlying trends-submission to authority, unconscious handling of hostility toward authority by means of displacement and projection onto outgroups, and so on-as his ethnocentrism [...] This is not merely a "modern conservatism." It is, rather, a totally new direction: away from individualism and equality of opportunity, and toward a rigidly stratified society in which there is a minimum of economic mobility and in which the "right" groups are in power, the outgroups subordinate. Perhaps the term "reactionary" fits this ideology best. Ultimately it is fascism.

The level of contestation over Hofstadter's position on Populism reflects the level of disagreement among historians about this movement. Johnston (2007) outlines much of this discussion but asserts that Hofstadter was correct to assert the presence of reactionary voices in Populism whilst acknowledging that they sat uncomfortably alongside voices that were forerunners of the Progressive movement that was to follow. Johnston's point is simple: that U.S. populism incorporates a variety of stances in its criticism of the established order. Certainly, these stances include 
democratic perspectives that seek to promote the realization of the aspirations of all Americans but, at the same time, anti-semitism and a belligerent nationalism were also present,

[T] he Populist moment of the 1890s bequeathed to its various populist successors a suspicion of elites and a taste for conspiratorial explanations that have at times nurtured antisemitism and other forms of bigotry. (Johnston 2007, 133)

More well-known and equally apposite here is Hofstadter's study of conspiracy theory "The Paranoid Style in American Politics." Effectively a survey of conspiracy theory in American culture and politics and a brief study of the John Birch Society (JBS), it shaped subsequent scholarly discussion of conspiracy theory by situating the "paranoid" beliefs of the JBS in a long-standing - if inchoate - tradition of alternative explanations for social, political, economic, and cultural change. Like Hofstadter's commentaries on the differing modalities of conservatism this essay has had a lasting legacy but has attracted criticism. Typical of recent criticism is Fenster's charge that Hofstadter pathologizes conspiracy thinking. Fenster $(2008,8)$ suggests that Hofstadter contrasts conspiracy thinking with a "healthy" approach to politics, and "he implied that conspiracy theory constitutes a malady or affliction." Despite his otherwise excellent study, Goldberg (2001) goes further in this reductionist reading of Hofstadter; his reading of "the paranoid style" is wholly grounded in the idea of Hofstadter as a diagnostician. He writes, 
Hofstadter donned the white coat of a clinician. Conspiracy theorists were marginal men and women whose personality disorders caused them to project their problems, status grievances, and wounds into public affairs. (Goldberg 2001, xi)

Goldberg continues in this vein and uses the language of a "clinician" to emphasizes his charge against Hofstadter: "cure," "contagious," "infect," "fever." This is all hyperbolic; this shibboleth needs laying to rest. Hofstadter himself is careful to make clear he is not using the term in its full medical sense but rather as an analogy suggestive of a tendency to identify otherwise indiscernible threats to the "normal" run of things. It is characterized by the conspiracy theorist's production of fear of hidden agency subverting a way of life. Hofstadter $(1964,77)$ is clear on his avoidance of the medical implications that the term might otherwise indicate:

I am not speaking in a clinical sense, but borrowing a clinical term for other purposes. I have neither the competence nor the desire to classify any figures of the past or present as certifiable lunatics. In fact, the idea of the paranoid style as a force in politics would have little contemporary relevance or historical value if it were applied only to men with profoundly disturbed minds.

Nonetheless, despite this clarity caricatures like Goldberg's persist. Peter Knight's $(2000,31)$ discussion of Hofstadter also confines him to the clinical metaphor, insisting that Hofstadter produces a "diagnosis of a thoroughgoing paranoid delusion," and goes on to suggest that Hofstadter "insisted" that the paranoid style is "a minority phenomenon" (Knight 2000, 
36), but again, this needs to be addressed because it undermines the opportunity to draw on Hofstadter's analysis in order to better understand times to which it is suited, including our own.

Hofstadter does describe the "spokesman" [sic] of the paranoid style as being marginal but here his ascription of a marginal status does not downplay the seriousness of his discourse. This marginality is better understood as being reflective of Daniel Bell's (1963) suggestion that the U.S. radical right represented a "dispossessed" constituency. As discussed above, Hofstadter contributed essays on the "pseudo-conservatives" to Bell's collection; he also refers to Bell's own essay in "The Paranoid Style in American Politics." Here, he is quite clear that the right wing tendency in which he identifies a proclivity for the use of the paranoid style is subject to social rather than psychological stresses, "but the modern right wing, as Daniel Bell has put it, feels dispossessed: America has been largely taken away from them and their kind, though they are determined to try to repossess it" (Hofstadter 1964, 81). Thus, marginality in this instance reflects a social status. It is worth quoting at length from Hofstadter in order to restore this social dimension to understandings of his work in current academic work on conspiracy theory. What is key in the following is that Hofstadter does not condemn "the paranoid style" to the marginalia of history but, quite correctly, acknowledges its capacity to command influence in periods of generalized anxiety regarding social status or economic 
Secrecy and Society, Vol. 1, No. 2 [2018], Art. 1

security. He writes that while a tendency to subscribe to a conspiracy view of history may be seen to be,

[M]ore or less constantly affecting a modest minority of the population. But certain religious traditions, certain social structures and national inheritances, certain historical catastrophes or frustrations may be conducive to the release of such psychic energies, and to situations in which they can more readily be built into mass movements or political parties. In American experience ethnic and religious conflict have plainly been a major focus for militant and suspicious minds of this sort, but class conflicts also can mobilize such energies. (Hofstadter 1964, 86)

It is clear here that Hofstadter, in his conclusion, is warning of the risk of the spread of "paranoid rhetoric" from the perennial social margins into the mainstream. In this he is not far off the analyses of the more recent commentators who have, generally, sought to dismiss Hofstadter. Aupers (2012) takes this tack and, without offering any evidence, introduces a suggested Freudian dimension to Hofstadter's undeserved reputation as a diagnostician of aberrant political views. Aupers' dismissal of Hofstatder's work typifies the recent tendency to attempt an ostensibly more considered approach to conspiracy; similar approaches can be found in Knight (2000), Fenster (2008), Robertson (2015). As such, it is worth exploring a little further. Aupers' argument is that Hofstadter's diagnostic approach is predicated on an assumption that conspiracy theory represents a dangerous challenge to the consensus politics preferred by Hofstadter. Aupers (2012, 23) contends that Hofstadter, along with Daniel Pipes (1997) and Fredric Jameson (1991) reflect "the ideology of modern Enlightenment," and 
produce a simplistic and inaccurate division between the rational modern subject and the irrational pre-modern alternative, echoing Weber's disenchantment thesis. Following Peter Knight (2000), he sees this as approaching the status of a moral panic about the decline in public reason and suggests that, instead, conspiracy theory reflects a more generalised suspicion of authority and loci of power, "'Paranoia' is no longer simply a diagnostic label applied by psychologists and psychiatrists but has become a veritable sociological phenomenon" (Aupers 2012, 23).

This has become something of a common assumption in academic treatments of conspiracy theory. Conspiracy theory is increasingly treated as a commonplace disposition that typifies a diminished public capacity to apply reason and a falling away in trust between citizens and the state. However, within this, there are variations on this theme. Clarke (2002) considers the "attributional error" implicit in conspiracy to have potential value with conspiracy theorists' activities creating pressure on state agencies to operate in a more open manner. Indeed, the academy may do well to listen to his suggestion that, "The conspiracy theorist challenges us to improve our social explanations. If a nonconspiratorial social explanation is better articulated as a result of the challenge of a conspiracy theory then that is all to the good" (Clarke 2002, 148). However, he is wrong to diminish the risk that conspiracy theories present. Clarke $(2002,148)$ suggests that "few are actually harmful," but it needs to be acknowledged that a conspiratorial 
Secrecy and Society, Vol. 1, No. 2 [2018], Art. 1

theory of history was a contributor to the spread of anti-Semitism in Europe during the early part of the Twentieth Century. Cohn (1966) and Bronner (2000) provide a reminder of the influence of The Protocols of the Elders of Zion had during the Nazi era. Moreover, in line with other works (Barkun 2003, Wilson 2017) Bronner underscores the continued utility to the far right that The Protocols provides.

Following Michael Rogin's (1967) earlier work, Fenster (2008) divides academic commentaries on conspiracy thinking into two camps, symbolists and realists. The division is organized around the idea that academic writing about conspiracy theories generally serves two purposes: symbolists reflect centrist countersubversion and realist interest in conspiracy theory lies in delineating the ideological use of conspiracy theory by elite groups. Like Rogin, Fenster describes Hofstadter as a symbolist and, rightfully, praises his approach for situating conspiracy theories in their historical social, economic, and political contexts but, tiresomely, does so in the "Hofstadter as clinician" vein. Fenster $(2008,51)$ criticises realists for their, "too-quick dismissal of conspiracy theory as a popular political practice," and that their concentration on the instrumental uses of conspiracy theory obscures the initial circumstances that led to the politicisation of the advocates of conspiracy theory in the first place. This is certainly true but, equally, Fenster is overly hasty to err on the side of caution and extend the benefit of 
the doubt to conspiracy theorists in the name of open-mindedness. Fenster $(2008,90)$ writes that

[C]onspiracy theories may be wrong or overly simplistic, but they may sometimes be on to something. Specifically, they may well address real structural inequities, albeit ideologically, and they may well constitute a response, albeit in a simplistic and decidedly unpragmatic form, to an unjust political order, a barren or dysfunctional civil society, and/or an exploitative economic system.

This is undeniable but by constructing and then writing dismissively of the so-called realist approach he diminishes the capacity to recognize that in the overly simplistic forms that conspiracy thinking can take there is a danger that the simplification produces potentially dangerous divisions within society. Whilst Fenster is right to highlight the capacity for conspiracy thinking to bring to light the grievances of a community it does not follow that this necessarily legitimizes conspiracy thinking as a reasonable response. As will be demonstrated, the danger in linking populism and conspiracy theory that Hofstadter outlines does pose an opportunity for potentially violent extremists to exploit and radicalize popular dissent. Fenster is not alone in seeking to limit the perception of threat associated with conspiracy thinking. Similarly, Knight (2000) plays down the adversarial conspiracist outlook that Hofstadter delineated in pseudo-conservatives and the John Birch Society. Instead, Knight $(2000,75)$ insists that what was once the domain of the radical is now a mainstream reticence to extend trust or belief, 
Paranoia is no longer necessarily the mark of right-wing demonological extremism [...] it has become a default attitude for the post-1960s generation, more an expression of inexhaustible suspicion and uncertainty than a dogmatic form of scaremongering.

Knight suggests that the populist, white right-wing forms of conspiracy thinking had become dissipated and indistinguishable from those shared by other social groups. He does this in a discussion of The Turner Diaries (1978), a race war fantasy novel written by the founder of the National Alliance, William Luther Pierce, under the pen name Andrew Macdonald. The novel depicts a guerrilla war waged by white nationalists in a future in which whites are routinely persecuted in a Jewish-run United States. Knight's analysis suggests that this is a response to the diminished position of the white working class within an economic and political context that has made equivalent the lives of all working people by destabilizing working class jobs and creating an equality of precariousness. Knight $(2000,42)$ writes,

the increasing competition for diminishing social resources amongst so-called minority groups leads to mutual suspicions between the disinherited [...] even the white Anglo male establishment now seeks to redefine itself as an embattled minority interest group in the face of a larger conspiracy group.

Furedi (2005) also embraces this model of an increased mainstreaming of conspiracy theory as marking a particular mode of subjectivity. He frames this as a crisis in agency, writing, "No one is as they seem. This normalization of suspicion and mistrust does not possess any critical 
dimension. Agency panic represents the fear that the vulnerable subject bears towards an incomprehensible changing world" (Furedi 2005, 86). What is distinct in Furedi's $(2005,86)$ analysis is that whilst he embraces the generalised position he is still quite clear that conspiracy theory represents an analytical failure, describing it as a "simplistic worldview," that, "displaces a critical engagement with public life with a destructive search for the hidden agenda."

Barkun's (2003) detailed survey of American conspiracy culture in the new millennium recognized this generalized mistrust of traditional institutions and channels of communication. Nonetheless, whilst recognizing that a conspiracy view of history is present on both the left and right wing he is clear that how this outlook is made manifest is quite distinct in each instance. So, for example, in a discussion of the shared aspects of New World Order conspiracies he notes that those on the left are fearful of a restriction of rights and freedoms whilst those on the right are more likely to frame their conspiracy theories in terms of a direct persecution of themselves and their political allies. Barkun $(2003,72)$ writes, "the right $[\ldots]$ became obsessively concerned with the risk of their own incarceration."

The theme of persecution by a socialist "New World Order" is a wellestablished one on the right. Pat Robertson's (1991) use of this theme is well-documented and formed the basis of his book The New World Order. The book spent weeks in The New York Times non-fiction bestsellers list 
Secrecy and Society, Vol. 1, No. 2 [2018], Art. 1

during November and December 1991. This popularity led Michael Barkun (1996) to describe it as one of two dominant factors behind the mainstreaming of populist nationalist conspiracy theories during the 1990s. The other factor he cited was the active presence on the Internet of the Militia movement; in the case of the Militias, he observed the commingling of conspiracism with Robertson's millenarian apocalypticism leading to a fervent urgency within their outlook. Thus, the conspiracism that was spread by members and sympathizers of the Militia movement was marked by an eschatological right wing outlook and it was this that characterized the mainstreaming of conspiracy theory as an actual phenomenon as opposed to the more general skepticism characterized by fictional forms such as The $X$ Files. Barkun $(1996,61)$ observed that "beliefs once consigned to the outermost fringes of American political and religious life now seem less isolated and stigmatizing than they once did." This observation is developed by Nigel James (2001) in a chapter examining the Militia/Patriot movement's use of the Internet. In this, he also draws on Zygmunt Bauman's (1998, 1999,2001 ) work on the erosion of prior sureties of identity by the dissolution of closed cultural systems brought about via relatively easy access to rapid intercontinental travel and global communications networks, particularly the Internet. Like Oliver and Wood (2014), James notes the tendency within the conspiracy milieu for conspiracy theorists and their followers to exhibit a pronounced Manichaeism in their worldviews. Following 
Bauman, he suggests that this becomes coupled with a retreat into a belligerent nationalism as a defense against the unbearable freedom to endlessly recreate the self that characterizes postmodern identities. It is, nonetheless, an ambivalent nationalism that accentuates loyalty to "the nation" but this is qualified by the mistrustful antagonism toward the state found within conspiracism. James $(2001,83)$ provides a useful reminder that the recursive interlinking of websites and Internet-based methods of communication produce a virtual proximity in beliefs that are otherwise marginalised: "the occultist/UFO/Egyptologist/quasi-religious vortex of belief systems [is] never more than a few clicks away from a neo-Nazi or Christian Identity website."

\section{The Internet, \#whitegenocide and the Radical Fringe}

The Internet has provided an ideal medium for the dissemination of all manner of stigmatized knowledge and provided fringe groups and beliefs a potential audience that far exceeds the network of self-published magazines, fairs and speaking opportunities that Colin Campbell (1972) described as "the circuit" by which the cultic milieu recruited during the 1970 s. Whilst the content of the message being circulated may be analogous, the reach of fringe voices via global communication media exceeds the audiences in town halls and mail order publications by several magnitudes. Barkun (1996, 2003) raises this point, and returns to it in his consideration of the 
prevalence of conspiracy themes in Donald Trump's campaigns for Republican presidential candidate and U.S. President (Barkun 2017). In this short essay, Barkun reinforces his earlier point regarding the capacity for the Internet to amplify the voices of the bearers of stigmatized knowledge. He points to the capacity the web gives for republishing the same material on any number of platforms (or spamming as it is more usually called), also for the Internet to provide those with a little technical savvy to present their ideas in a polished manner that belies their fringe origins, and also the opportunity for "securing pseudo-credibility" (Barkun 2017, 438) by being linked to be a more credible, mainstream source. In particular, though, he pays heed to the capacity for Web the 2.0 platforms such as Twitter and Facebook to accelerate the process of what he calls "the mainstreaming of the fringe" (Barkun 2017, 441). Barkun identifies the Trump's use of former Breitbart executive chair Steve Bannon as strategist in his campaign and presidency as a clear sign of a more generalised acceptance of far right fringe beliefs in the political mainstream; he describes Bannon and his connection with the alt-right as providing, "a bridge to the fringe" (Barkun 2017, 440). He might equally have mentioned Trump's conversations with Alex Jones.

The Trump campaign was galvanized by support from the "alt-right". The alt-right is a relatively recent political formation within U.S. right wing circles. Whilst sharing some of the social conservativism of the religious 
right, the alt-right is marked by a comparative youthfulness and a radicalism in its racial politics. It is also marked by a nebulousness that prevents an easy ideological mapping and it is notable that its amorphousness can be at least attributed to its origins in the anonymous Internet message boards, 4chan and 8chan. There is a willed boundary pushing that tests freedom of speech in a progressive liberal environment; "political correctness" is one of the alt-right's bugbears and the ludic nihilism of troll culture in $4 / 8$ chan has been given some political grounding by the alt-right. In this, \#Gamergate is a clear precedent of the alt-right in its coupling of online trolling and reactionary attitudes to gender roles. Similarly, the exhortations to "transgress" made by Milo Yiannopoulos is clearly a targeted attack on the liberal values that have influenced sections of the U.S. mass media and national politics for the last decade. Although the rapid ascendency of the alt-right has precluded the opportunity for an extended academic literature certain thematic similarities have begun to emerge. Barkun $(2017,439)$ is unequivocal in his description of the alt-right and notes that despite being "a somewhat ill-defined label comprising white separatists, both anti-Semitic and non-anti-Semitic." Rosenfeld echoes this, but goes further in her characterization of the radical nature of the alt-right incursion into the mainstream. She views this fringe as proto-fascistic and a danger to the future of the U.S., and writes, "Bannon regards his revolution - a 'global Tea Party movement'-as a quintessentially spiritual movement that will return 
the West to its ancestral ('Judeo-Christian') culture" (Rosenfeld 2017, 13). In doing so she purposefully invokes Mussolini and her essay proliferates with justified references to the Fascistic leanings and influences apparent in the alt-right movement. Civil rights activists and the Southern Poverty Law Center detail a number of the celebratory statements made by notable figures on the alt-right in the wake of Trump's victory (Piggott 2016). Many of these are expressed in ethno-nationalist terms confirming the alt-right's grounding in diverse white nationalist groups.

As has been detailed elsewhere, one of the unifying cornerstones of white nationalist ethno-nationalist is a millenarian conspiracism (Wilson 2012 , 2017). Wilson (2017) provides evidence of the purposeful use of the Twitter tag \#whitegenocide by users of the white nationalist web forum, stormfront.org. During the multiple ISIL terrorist attacks on Paris on the night of November 13, 2015 forum members posted messages encouraging readers to use the hashtag in tweets relating to the attacks. The messages provide a clear account of white nationalist use of Twitter as a means of amplifying their politics of hate by association with trending political events. The phenomenon of hashtag activism has attracted some academic attention and most of it has been laudatory in the strategic use of hashtags to counter normative narratives of race, ethnicity, and racialized (in)justice, predominantly on Twitter (Yang 2016; Bonilla and Rosa 2015; Cumberpatch and Trujillo-Pagán 2016). Yang $(2016,15)$ also notes the capacity for the 
shared use of the \#BlackLivesMatter to allow a creative communality of shared experiences to join together disparate experiences of injustice through a shared narrative form and, "create a collective story of struggles for racial justice." Bonilla and Rosa (2015) also note the collective endeavor that links hashtag activists but also draw attention to the extended reception these creative acts are afforded. Even though the replies and retweets may have been challenging or critical, they note the capacity for the \#Ferguson to mobilize attention to ongoing and widespread injustice in America:

Within this context, social media participation becomes a key site from which to contest mainstream media silences [...] social media users were able to show that "\#Ferguson is everywhere"-not only in the sense of a broad public sphere but also in the sense of the underlying social and political relationships that haunt the nation as a whole. (Bonilla \& Rosa 2015, 12)

Quite rightly, Bonilla and Rose, as with Yang and others, point to the potential for hashtag activism to disrupt normatively regulated flows of information and to counter the institutional power structures represented by the mainstream media. However, as Barkun $(1996,2003,2017)$ has shown, the open structures that allow the progressive use of the Internet and social media also provides an opportunity for reactionary voices to attempt the same. Thus, the communal effects of \#BLM and the disinterring of concealed racial "haunting" by \#Ferguson are employed by the alt-right through \# whitegenocide and other white power hashtags. 
Secrecy and Society, Vol. 1, No. 2 [2018], Art. 1

The following section explores current use of the hashtag and shows how text mining Twitter can enhance understanding of the situated use of \#whitegenocide hashtag to further strengthen the bridge between the fringe and the political mainstream as described above. Twitter's popularity clearly offers users a platform from which to address an extensive audience with 328 million monthly active users of whom $70 \mathrm{~m}$ are American, this represents just under a quarter (24\%) of all online American adults (Statista 2017). Although Twitter limits its archival database, text mining is able to make use of resources made available through Twitter search APIs (Application Programming Interface). In this instance, the free R statistical environment (R Core Team 2017) was used for the analysis. Additional R packages were used for Twitter API interaction (Gentry 2015), text mining (Feinerer \& Hornik 2017), topic modeling (Grün \& Hornik 2011), and visualization (Wickham 2009, Fellows 2014). 10,000 tweets using the \#whitegenocide were filtered using text parsing to remove common words that added little to the character of the tweets (conjunctions, prepositions, pronouns and so forth). A frequency matrix which was used to further filter words used less than 100 times. From here a wordcloud was generated to provide an at-a-glance reference of the 50 words most frequently used in tweets flagged with \#whitegenocide. 


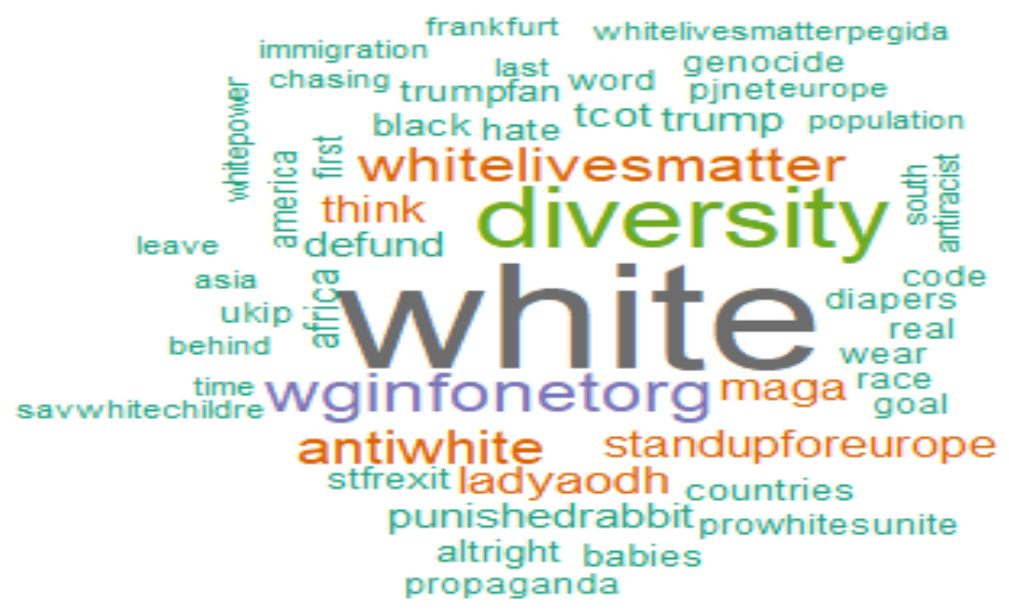

At the heart of the wordcloud are the two opposing terms in the white nationalist imaginary: white(s/ness/people/race) and diversity. The two poles in the white identitarians' Manichean divide between purity and plurality. What is also striking is the presence of a number of prominent altright Twitter users: @wginfonetorg (White Genocide Info), @ladyaodh (Ann Kelly "European rights activist"), @punishedrabbit1 (Jess Lynn, the number "1" is omitted from the wordcloud as numbers are not included in the term matrix), @savwhitechildre (SaveWhiteChildren). The latter is a clear reference to the " 14 words" of mystic white supremacist David Lane, "We must secure the existence of our people and a future for white children" (cited in Michael 2009, 43). The presence of these usernames among the most frequently used terms indicates the capacity for individual users to shape hashtag usage on Twitter. The audience reach of these users is also 
instructive. The following maps indicate the geographic distribution of the followers of the three most overtly white supremacist of these users.

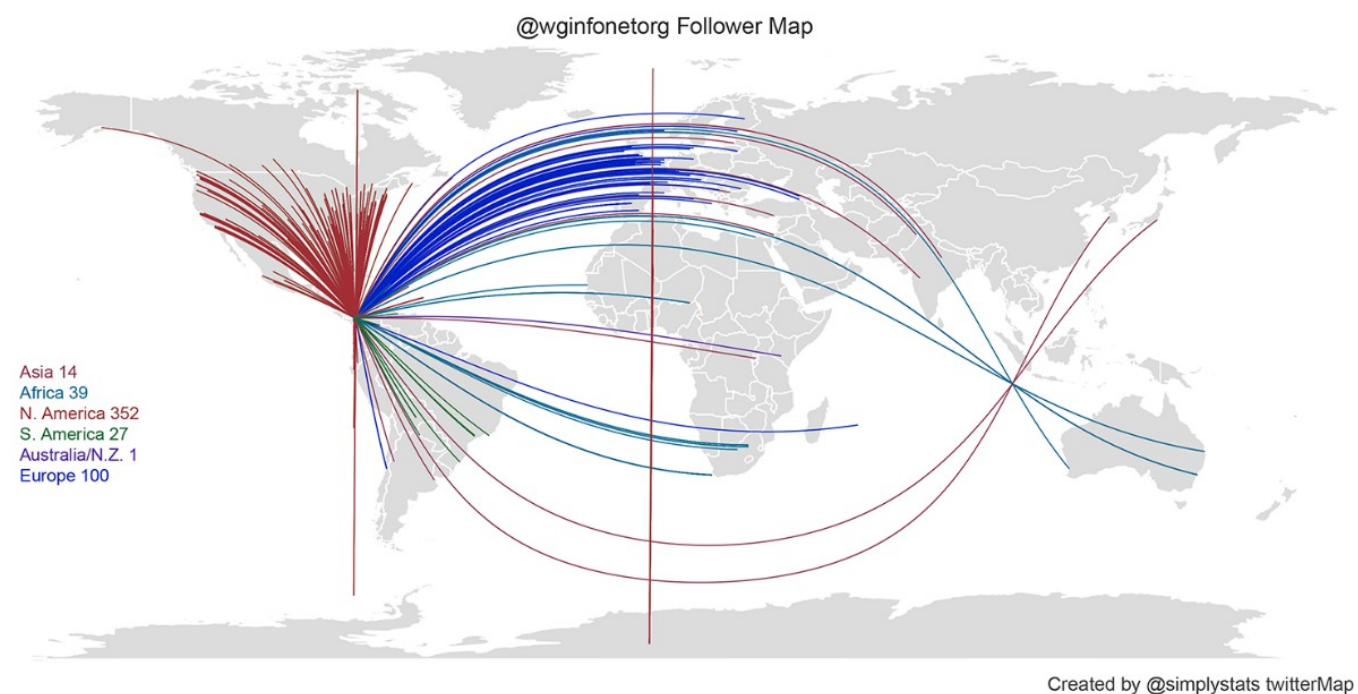

Map of followers for user White Genocide Info. Location of user estimated from linked Web site registrar information.

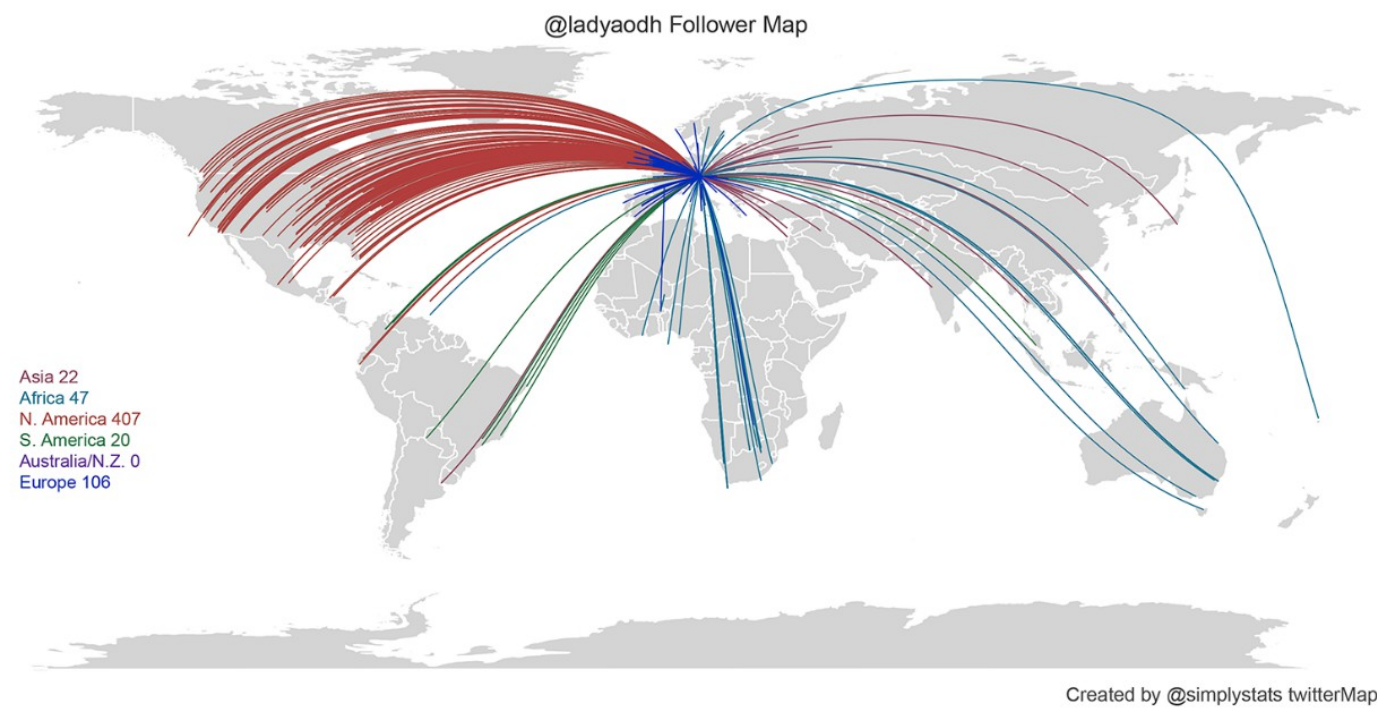

Map of followers for user Kelly Ann. Location of user estimated from linked website registrar information. 


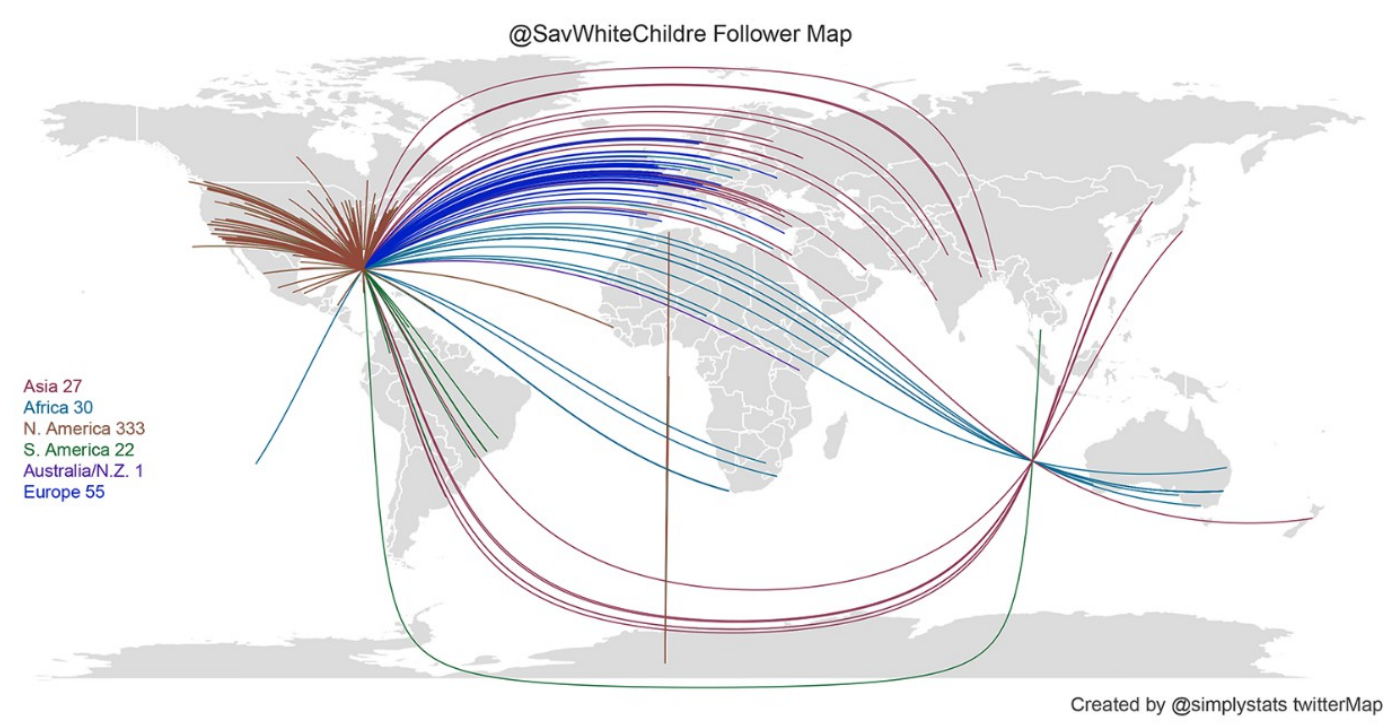

\section{Map of followers for user Save White Children. Location of user estimated from linked website registrar information.}

Although their locations are varied the three most notable \#whitegenocide posters all provide a link to a homepage offering white supremacist propaganda. The distribution of their audience is broadly comparable with roughly $70 \%$ of their followers based in the U.S. and in the cases of White Genocide Info and Kelly Ann a European following of roughly $18 \%$. Save White Children has a slightly smaller European following (11.8\%) and a more pronounced South American following. It must also be recognized that only a small percentage of their following provide a geographic location and so the maps above are limited in their scope. For instance, only $2.2 \%$ of Kelly Ann's c. 26.5 thousand followers 
provide a location that was identifiable by the $\mathrm{R}$ source code, TwitterMap (Leek 2011). Nonetheless, the broad point is that if there is an equal distribution of users providing geographic locations, in all three instances their potential audiences are global.

The word cloud procedure was repeated with the usernames of the individual removed from the term matrix. This brings a sharper focus on the variety of terms most frequently associated with the \#whitegenocide as can be seen below:

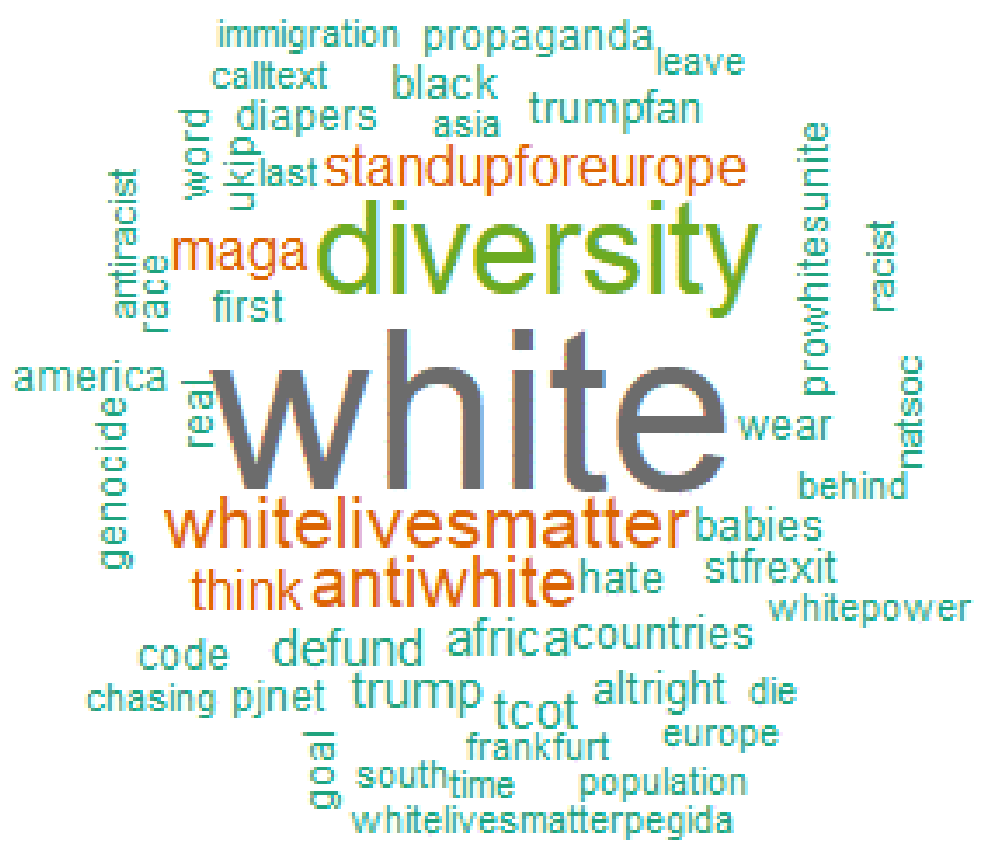

Three of the five third tier terms (after the Manichean binary, "white" and "diversity") are hashtags: \#WhiteLivesMatter, \#StandUpForEurope, and \#MAGA. The first two are alt-right activist hashtags whilst the latter is President Trump's campaign slogan "Make America Great Again." 
\#MAGA is a close tie for the fifth most frequently paired term with \#whitegenocide. The following chart demonstrates the frequency distribution of terms used in more than 200 \#whitegenocide posts from the sample.

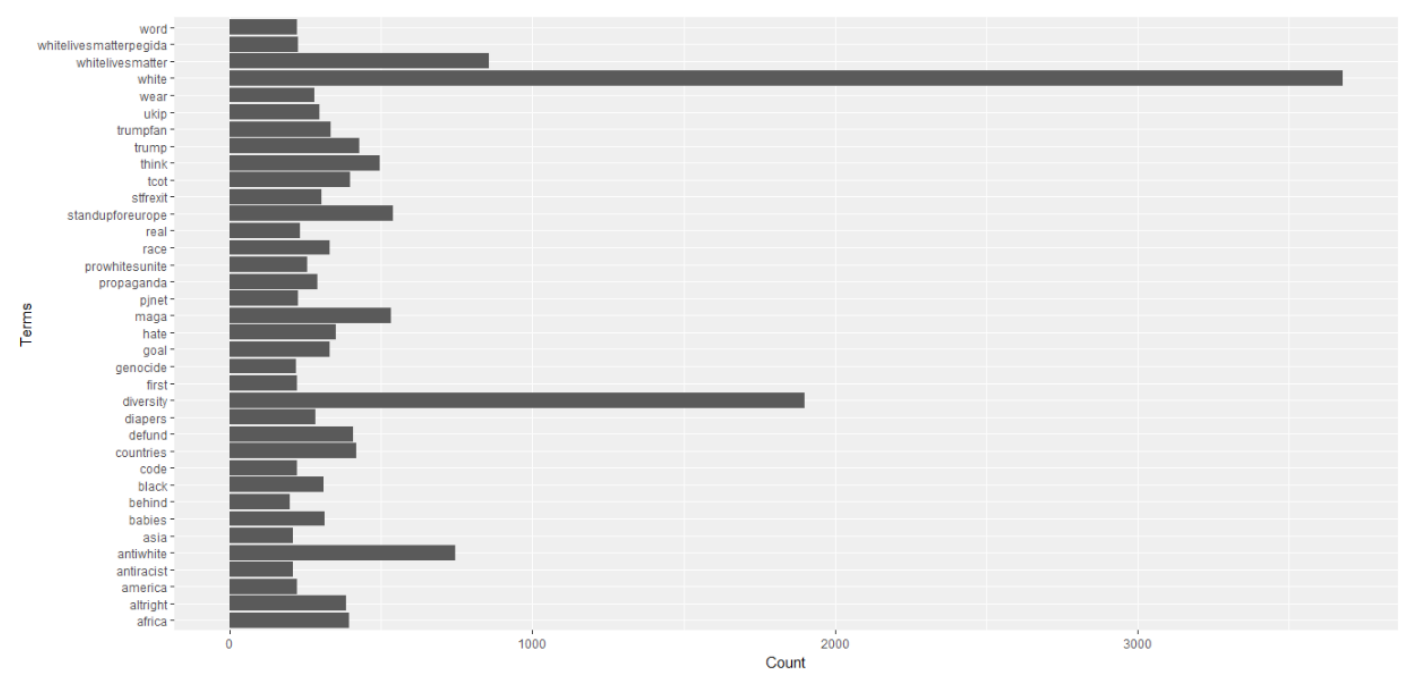

Other frequently occurring hashtags include \#tcot ("Top Conservatives on Twitter") and \#pjnet ("Patriotic Journalists Network"). The strategy here is clear. \#whitegenocide is being repeatedly used in proximity to more mainstream hashtags as a mechanical means to effect the bridging from the fringe to the mainstream outlined above. Trump is a clear conduit and it is no great surprise that he features in the 50 terms most frequently associated with \#whitegenocide. His prevarications on matters of race and his relationship with the alt-right have ensured that the bridge to the mainstream continues to be available to the fringes of the right wing. A frequency analysis of terms most frequently associated with \#maga in the dataset of tweets 
featuring \#whitegenocide shows the following to be the most frequently associated terms:

$\begin{array}{llllllll}\text { tcot } & \text { whitepow } & \text { natsoc } & \text { ccot } & \text { trump } & \text { altrig } & \text { hate } & \text { pjnet } \\ \text { er } & & & & \text { ht } & & \\ .58 & .57 & .56 & .43 & .41 & .40 & .37 & .33\end{array}$

There is a clear divide in these between overtly radical rights stances and the more traditional conservative right but the location of \#maga and Trump vacillate between the two and are revealed as the bridges between the mainstream and the fringe described in Barkun. For clarity, these can be organized in the following table:

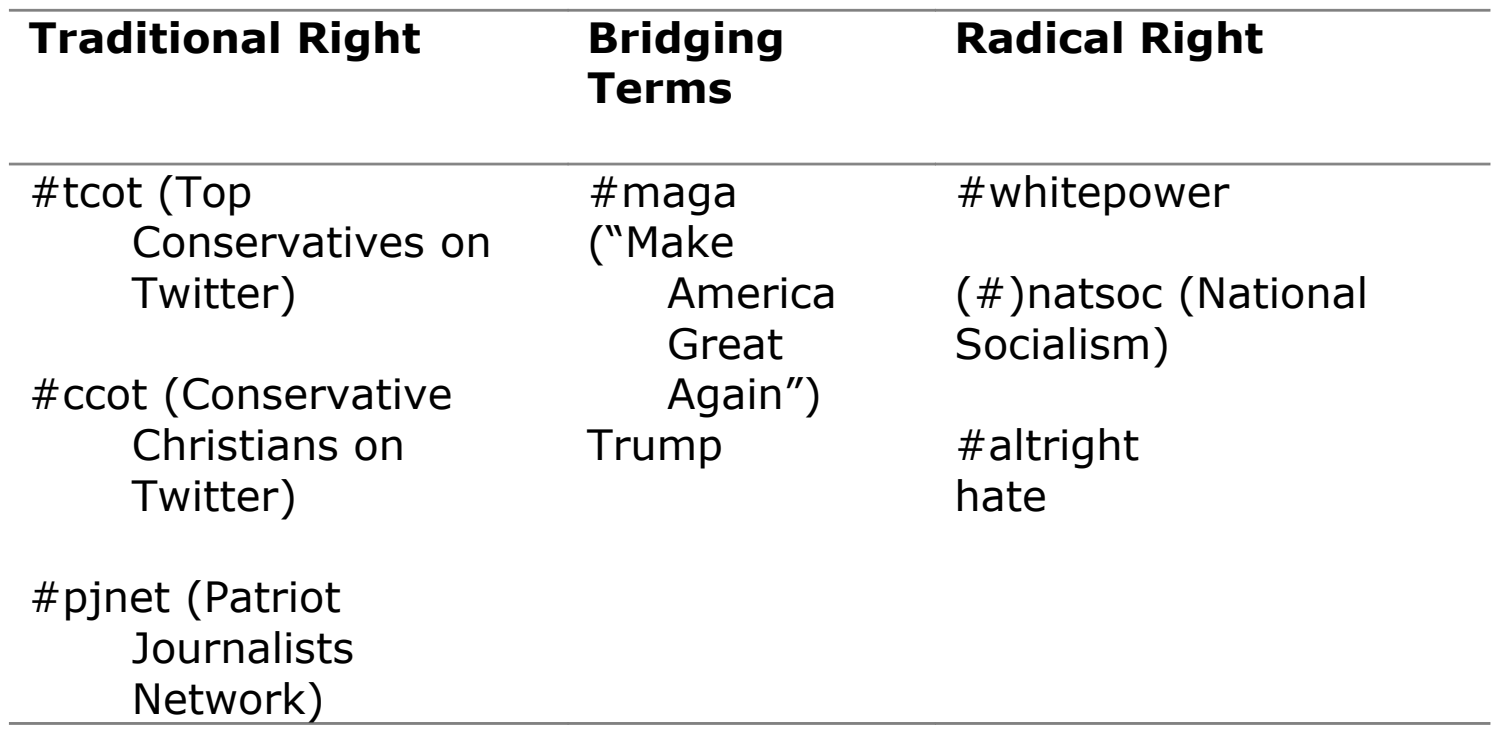

Echoing the division between "genuine conservatives" and "pseudo-conservatives" made by Hofstadter, Barkun's fringe increasingly find ways into the mainstream of American politics and shift the 
discourse of conservatism in a more radical direction. As was indicated above, in the conclusion of "The Paranoid Style" Hofstadter $(194,86)$ warned of the susceptibility of the capacity for conspiracist rhetoric to be "built into mass movements or political parties." Wittingly or not, Trump's rhetoric has galvanized the radical right as they set their sights on mainstream acceptance.

\section{Concluding Comments}

The compounding and expansion of state secrecy during the Cold War and the War on Terror produced an era of mistrust and generalized suspicion described by Fenster, Knight, and Aupers. Not unreasonably, they signal conditional approval for the skepticism toward loci of power/knowledge within the modern state and globalized corporate entities that conspiracy theory represents; although their approval is tempered by the more outré claims of fringe conspiracy theories. Nonetheless, the dismissal of Hofstadter's work as an operation in clinical diagnosis has correspondingly resulted in an unpreparedness for the exploitation of this "culture of conspiracy" by the radical fringe. It should be noted here that conspiracies do exist and that conspiracy theories are not the preserve of the political right. Covert actions are, arguably, a necessary part of statecraft but their distinction from conspiracies is determined only by the legitimacy of the power that is exerted in their enaction. At the same time, fanciful accounts of the 
secret exertion of power to achieve grand, malevolent ends abound. What is of note in our moment is the spread of conspiracy theories into the mainstream. In their turn to conspiracy theory, the radical right have conformed to the "diagnosis" made by Hofstadter.

To return to Hofstadter's article on the paranoid style, it is notable that he dedicates a subsection to the paranoid spokesman's habit of "Emulating the Enemy." Among the Ku Klux Klan, anti-Communists, anti-Catholics, and anti-Masons' reproduction of the tactics or organisational structures of their perceived enemies, Hofstadter $(1964,85)$ also describes how "the John Birch Society emulates Communist cells and quasi-secret operation through "front" groups, and preaches a ruthless prosecution of the ideological war along lines very similar to those it finds in the Communist enemy." The parallels with the alt-right's reproduction of \#BlackLivesMatter in its reversed form as \#WhiteLivesMatter is clearly a maneuver in this tradition and might be understood to represent a desire to emulate and claim a parallel creative community to the one described by Yang (2016). Although this simple mimicry is more redolent of the fragile desperation with which the alt-right seeks a consistent, communal "white" identity than it is of a developed political strategy. Nonetheless, political progressives would be well advised to dismiss the continued hashtag activism of the alt-right at their peril. Whilst this article was being completed President Trump gave a 
public speech to a crowd in Warsaw, Poland ahead of the G20 Summit in Hamburg, Germany. He told the crowd,

The fundamental question of our time is whether the West has the will to survive? [...] Do we have the confidence in our values to defend them at any cost? Do we have enough respect for our citizens to protect our borders? Do we have the desire and the courage to preserve our civilization in the face of those who would subvert and destroy it?" (Thrush \& Davis 2017, §6)

Trump's association with the alt-right leaves little room to doubt that his "West" is a white West. His rhetoric is at once that of the paranoid spokesman trafficking "in the birth and death of whole worlds, whole political orders, whole systems of human values. He is always manning the barricades of civilization" (Hofstadter 1964, 82). Certainly, Huntington's (1993, 1996) clash of civilizations casts a long shadow over this rhetoric, but in light of the enmeshed hashtags, the proximity of the alt-right to the White House, and Steven Bannon's strategic role, it is not unreasonable to suppose there will be an audience for Trump's words that hears not Huntington's influence in Trump's words, but that of William Pierce, David Lane's 14 words, or \#whitegenocide. 


\section{References}

Adorno, Theodor W., Else Frenkel-Brunswik, Daniel J. Levinson, and Robert Nevitt Sanford. 1950. The authoritarian personality. New York: Harper.

Aupers, Stef. 2012. "Trust no one": Modernization, paranoia and conspiracy culture. European Journal of Communication 27, no.1 :2234.

Barkun, Michael. 1996. Religion, militias and Oklahoma City: The mind of conspiratorialists. Terrorism and Political Violence 8, no.1 : 50-64.

Barkun, Michael. 2003. A culture of conspiracy: Apocalyptic visions in contemporary America. Berkeley: University of California Press.

Barkun, Michael. 2017. President Trump and the "fringe." Terrorism and Political Violence 29, no. 3: 437-443.

Bauman, Zygmunt. 1998. Culture as praxis. London: Sage. . 1999. In search of politics. Cambridge: Polity Press.

. 2001. Community: Seeking safety in an insecure world. Cambridge: Polity Press.

Bell, Daniel. 1963. The dispossessed. In The radical right: The new American right, edited by Daniel Bell. New York: Doubleday.

Blake, Aaron. 2017. Kellyanne Conway says Donald Trump's team has "alternative facts," which pretty much says it all. The Washington Post, January 22. https://www.washingtonpost.com/news/thefix/wp/2017/01/22/kellyanne-conway-says-donald-trumps-team-hasalternate-facts-which-pretty-much-says-it-all/ 
Bonilla, Yarimar, \& Jonathan Rosa. 2015. \#Ferguson: Digital protest, hashtag ethnography, and the racial politics of social media in the United States. American Ethnologist 42, no.1: 4-17.

Bronner, Stephen E. 2007. A rumor about the Jews: Antisemitism, conspiracy, and the Protocols of Zion. Oxford: Oxford University Press.

Campbell, Colin. 1972. The Cult, the cultic milieu and secularization. In $A$ Sociological Yearbook of Religion in Britain 5. London: SCM Press.

Clarke, Steve. 2002. Conspiracy theories and conspiracy theorizing. Philosophy of the Social Sciences 32, no. 2:131-150.

Cohn, Norman. 1970. The pursuit of the millennium, 2nd ed. Oxford: Oxford University Press.

Collins, Robert M. 1989. The originality trap: Richard Hofstadter on Populism. Journal of American History 76, no. 1: 150-167.

Cumberpatch, Prudence, \& Nicole Trujillo-Pagán. 2016. Hashtag activism and why \#BlackLivesMatter in (and to) the classroom. Radical Teacher 106:78-86.

Dobratz, Betty A., \& Stephanie L. Shanks-Meile. 2000. The white separatist movement in the United States. Baltimore: The John Hopkins University Press.

Durham, Martin. 2007. White rage: The extreme right and American politics. London: Routledge.

Feinerer, Ingo \& Hornik, Kurt. 2017. tm: Text mining package. R Package Version 0.7-1. https://CRAN.R-project.org/package=tm 
Fellows, Ian. 2014. Wordcloud: Word clouds. Version 2.5. https://cran.r-project.org/web/packages/wordcloud/index.html

Fenster, Mark. 2008. Conspiracy theories: Secrecy and power in American culture. Revised and updated. Minneapolis: University of Minnesota Press.

. 1999. Conspiracy theories: Secrecy and power in American culture. Minneapolis: University of Minnesota Press.

Furedi, Frank. 2008. Politics of fear: Beyond left and right. London: Continuum.

Gardell, Mattias. 2003. Gods of the blood: The pagan revival and white separatism. Durham, NC: Duke University Press.

Gentry, Jeff. 2015. twitteR: R based Twitter client. Version 1.1.9. https://cran.r-project.org/web/packages/twitteR/index.html

Goldberg, Robert A. 2001. Enemies within: The culture of conspiracy in modern America. New Haven, CT: Yale University Press.

Goodrick-Clarke, Nicholas. 2002. Black sun: Aryan cults, Esoteric Nazism, and the politics of identity. New York: New York University Press.

Grün, Bettina and Hornik, Kurt. 2011. topicmodels: An R package for fitting topic models. Journal of Statistical Software, 40, no.13: 1-30.

Haberman, Maggie. 2016. Alex Jones, host and conspiracy theorist, says Donald Trump called to thank him. The New York Times, November 22. https://www.nytimes.com/2016/11/17/us/politics/alex-jones-trumpcall.html 
Hellinger, Daniel. 2003. Paranoia, conspiracy, and hegemony in American politics. In Transparency and conspiracy: Ethnographies of suspicion in the New World Order, edited by Harry G. West and Todd Sanders. Durham, NC: Duke University Press.

Hofstadter, Richard. 1963. The pseudo-conservative revolt. In The Radical right: The new American right, edited by Daniel Bell. New York: Doubleday.

. 1964. The paranoid style in American politics. Harper's Magazine, November: 77-86.

. 1965. Pseudo-conservatism revisited - 1965. In The paranoid style in American politics and other essays. New York: Alfred A. Knopf.

Huntington, Samuel P. 1993. The clash of civilizations? Foreign Affairs 72, no. 3:22-49.

. 1996. The clash of civilizations and the remaking of world order. New York: Simon \& Schuster.

James, Nigel. 2001. Militias, the Patriot movement, and the Internet: The ideology of conspiracism. In The age of anxiety: Conspiracy theory and the human sciences, edited by Jane Parish and Martin Parker. Oxford: Blackwell/The Sociological Review.

Jameson, Fredric. 1988. Cognitive mapping. In Marxism and the interpretation of culture, edited by Cary Nelson and Lawrence Grossberg. Urbana and Chicago: University of Illinois Press.

1991. Postmodernism, or, the cultural logic of late capitalism. Durham, NC: Duke University Press. 
Johnston, Robert D. 2007. The age of reform: A defense of Richard Hofstadter fifty years on. The Journal of the Gilded Age and Progressive Era 6, no. 2: 127-137.

Kamiya, Gary. 2011. The infantile style in American politics. Salon, December 5.

http://www.salon.com/2011/12/05/the infantile style in american pol itics/

Kessler, Glenn. 2016. Trump's outrageous claim that "thousands" of New Jersey Muslims celebrated the 9/11 attacks. The Washington Post, November 22. https://www.washingtonpost.com/news/factchecker/wp/2015/11/22/donald-trumps-outrageous-claim-thatthousands-of-new-jersey-muslims-celebrated-the-911-attacks/

Knight, Peter. 2000. Conspiracy culture - from Kennedy to "The X-Files." London: Routledge.

Krieg, Gregory. 2016. 14 of Trump's most outrageous "birther" claims half from after 2011. CNN, September 16. http://edition.cnn.com/2016/09/09/politics/donald-trumpbirther/index.html

Leek, Jeff. 2011. Twittermap. https://github.com/vdimarco/twitterMap/blob/master/twitter.R

Liu, Xia, Alvin C. Burns, \& Yingjian Hou. 2017. An investigation of brandrelated user-generated content on Twitter. Journal of Advertising 46, no. 2: $236-247$

Maret, Susan. 2016. Contested Visions, Imperfect Information, and the Persistence of Conspiracy Theories. In Censored 2017, edited by Mickey Huff and Andy Lee Roth. New York: Seven Stories Press

Michael, George. 2009. David Lane and the Fourteen Words. Totalitarian movements and political religions 10, no.2: 43-61 
Oliver, J. Eric, \& Thomas J. Wood. 2014. Conspiracy theories and the paranoid style(s) of mass opinion. American Journal of Political Science 58, no.4: 952-966.

Pasek, Josh; Tobias H. Stark, Jon A. Krosnick, \& Trevor Tompson. 2015. What motivates a conspiracy theory? Birther beliefs, partisanship, liberal-conservative ideology, and anti-Black attitudes. Electoral Studies 40: 482-489.

Piggott, Stephen. 2016. White nationalists and the alt-right celebrate Trump's Victory. SPLC Hatewatch, November 9. https://www.splcenter.org/hatewatch/2016/11/09/white-nationalistsand-alt-right-celebrate-trumps-victory

Pipes, Daniel. 1997. Conspiracy: How the paranoid style flourishes and where it comes from. New York: The Free Press.

Rogin, Michael P. 1967. Intellectuals and McCarthy: The radical specter. Cambridge, MA: MIT Press.

Rosenfeld, Jean E. 2017. Fascism as action through time (or how it can happen here). Terrorism and Political Violence 29, no.3: 394-410.

R Core Team. 2017. R: A language and environment for statistical computing. R Foundation for Statistical Computing: Vienna, Austria. https://www.R-project.org/

Siddiqui, Sabrina. 2016. Donald Trump calls Obama the "founder of Isis." The Guardian, August 11. https://www.theguardian.com/usnews/2016/aug/11/donald-trump-calls-barack-obama-the-founder-of$\underline{\text { isis }}$

Statista. 2017. Twitter - statistics \& facts. https://www.statista.com/topics/737/twitter/ 
Sullivan, Andrew. 2010. Trying To understand the Tea Party II. The Dish, June 15. http://dish.andrewsullivan.com/2010/06/15/understandingthe-tea-party-ii/

Swift, Art. 2016. Americans' trust in mass media sinks to new low. Gallup, August 21. http://www.gallup.com/poll/195542/americans-trust-massmedia-sinks-new-low.aspx

Thrush, Glenn \& Davis, Julie H. 2017. Trump, in Poland, asks if West has the "will to survive." The New York Times, July 6. https://www.nytimes.com/2017/07/06/world/europe/donald-trumppoland-speech.html

Trump, Donald. 2012. Twitter post. November 6, 11:15am. https://twitter.com/realdonaldtrump/status/265895292191248385 2014. Twitter post. March 28, 5:35am. https://twitter.com/realdonaldtrump/status/449525268529815552

Wickham, Hadley. 2009. ggplot2: Elegant graphics for data analysis. Springer-Verlag: New York.

Wilson, Andrew F. 2012. The invisible empire: Political extremity and myths of origin in the networked cultic milieu. In Myth, mysticism, and "Celtic" nationalism, edited by Marion Gibson, Garry Tregidga and Shelley Trower. London: Routledge.

Wilson, Andrew F. 2017. The bitter end: Apocalypse and conspiracy in white nationalist responses to the ISIL Paris attacks. Patterns of Prejudice [Forthcoming]

Yang, Guobin. 2016. Narrative agency in hashtag activism: The case of \#BlackLivesMatter. Media and Communication 4, no. 4:13-17 
Wilson: \#whitegenocide, the Alt-right and Conspiracy Theory 